\title{
Depressão em jovens universitários
}

\section{Depression in university students}

\section{Sylvia Barreto}

Escola Bahiana de Medicina e Saúde Pública (Salvador). Bahia, Brasil. sylviabarreto@bahiana.edu.br

Os transtornos mentais ocorrem em todas as regiões e culturas do mundo sendo depressão e ansiedade os mais prevalentes. A depressão, embora seja um transtorno mental comum, é uma das principais causas de incapacidade e um dos principais contribuintes para a carga global de doenças. Mundialmente, mais de 264 milhões de pessoas de todas as idades sofrem de depressão, transformando-a em doença do século ${ }^{1}$. No Brasil, 5,8\% da população sofre de depressão, taxa acima da média global, que é de $4,4 \%{ }^{2}$.

Quando duradoura e com intensidade moderada ou grave, a depressão pode se tornar uma condição de saúde grave. O sofrimento de um indivíduo deprimido pode gerar dificuldades no trabalho, na escola, na família e no convívio social. Além de estar relacionada ao sofrimento e a automutilação, a depressão pode ser causa de risco aumentado de suicídio'.

Embora existam tratamentos eficazes e conhecidos para a depressão, entre $76 \%$ e $85 \%$ das pessoas em países de baixa e média renda não recebem tratamento. As taxas de reconhecimento da depressão permanecem baixas, tanto pelas pessoas acometidas, quanto pelos prestadores de cuidados de saúde, levando a apenas cerca de metade das pessoas com depressão receber qualquer tratamento, e cerca de $40 \%$ receber tratamento, porém considerado minimamente adequado ${ }^{2}$.

Sem um tratamento adequado, a depressão apresenta um curso crônico e recorrente. Estima-se que após o primeiro episódio o risco de recorrências seja de 50\%; após o segundo episódio este risco se eleva para 70-80\% e após três episódios depressivos, o risco de episódios seguintes é de $90 \%{ }^{1}$.

Barreiras ao atendimento eficaz incluem falta de recursos, dificuldade de acesso, falta de profissionais de saúde treinados e estigma social associado aos transtornos mentais. Outra barreira para o cuidado efetivo é a avaliação imprecisa, levando as pessoas deprimidas geralmente não serem diagnosticadas corretamente e outras pessoas que não sofrem desse distúrbio ser frequentemente diagnosticadas e prescritas com antidepressivos ${ }^{2}$.

Como a depressão geralmente pode começar quando as pessoas são jovens, ela pode afetá-las no auge de seus anos mais produtivos. As taxas de sintomas de depressão e ansiedade entre estudantes universitários são comuns em muitas regiões do mundo causando impacto na qualidade de vida e no desempenho acadêmico, representando assim um motivo de preocupação. 
Este fato leva cada vez mais as instituições de ensino superior a enfrentar taxas crescentes de transtornos mentais e, em muitos casos, a demanda por serviços no campus excede em muito os recursos disponíveis ${ }^{4}$.

O ingresso no ensino superior representa uma etapa de transição complexa envolvendo muitas dimensões e mudanças em várias áreas da vida dos jovens. Iniciar a graduação pode implicar em distanciamento da família, mudança de cidade, vínculo com novos grupos e diferentes demandas relacionadas a gestão do tempo e dos estudos. É no contexto universitário que o estudante se despede da adolescência e vai se tornando adulto ao construir sua trajetória acadêmica ${ }^{5}$.

Ao iniciar a vida acadêmica algumas expectativas são geradas e idealizadas pelos jovens e interferem na transição entre o ensino médio e a universidade. Elas estão diretamente associadas ao envolvimento com os estudos, as demandas interpessoais, a saúde psicológica e física e ao vínculo com a instituição de ensino superior. A vida acadêmica convoca os estudantes a refletirem e a se posicionarem de maneira diferente frente a autonomia, responsabilidade e a construção de diferentes vínculos interpessoais. Quando ocorre uma dissonância entre o que foi idealizado e a realidade no contexto acadêmico, frustrações podem ocorrer e afetar o desenvolvimento discente e as relações sociais, e se configurarem como eventos estressantes para os estudantes universitários ${ }^{6}$.

Em muitas situações, a presença de estressores pode interferir negativamente em vários aspectos da vida do jovem universitário e desencadear alterações de humor, como a depressão. A depressão é uma doença multifatorial que se caracteriza por perda de interesse nas atividades cotidianas e prazerosas, associase então a um estado de incapacidade e alteração dos processos cognitivos, afetivos e adaptação às condições da vida?

A depressão em estudantes universitários está relacionada à sobrecarga, desmotivação e a pressão acadêmica, afetando diretamente a qualidade de vida. Sua prevalência é em média, 30,6\% no referido público e na população em geral é de $9 \%$. É o transtorno mental que mais interfere na qualidade de vida, pelo fato de nem sempre ser identificada e tratada de maneira adequada. O diagnóstico da depressão não é fácil de ser realizado e envolve avaliação psiquiátrica, pois em muitos casos, os sintomas são confundidos com tristeza ou um episódio de luto?
Após o diagnóstico, o acompanhamento psicoterápico em conjunto com a intervenção medicamentosa dará ao jovem a oportunidade de compreender os motivos que o levaram a depressão, refletir sobre os referidos motivos e estabelecer estratégias de enfrentamento. Além da psicoterapia e psiquiatria, o estudante pode identificar outras estratégias de autocuidado, como a prática de atividade física ${ }^{8}$.

Em virtude da alta prevalência de depressão no cenário do ensino superior, os estudos sobre a saúde mental de jovens universitários vêm crescendo com o objetivo de compreender os referidos sintomas na população em questão e desenvolver ações com foco no fortalecimento da saúde mental dos jovens ${ }^{9}$.

As instituições de ensino superior precisam ampliar os espaços de discussão sobre a saúde mental do estudante universitário de maneira interdisciplinar. Os diversos atores envolvidos no ambiente acadêmico podem juntos refletir sobre o processo de ensino e aprendizagem com foco em novas metodologias e práticas, diferentes formas de avaliação e gestão do tempo. Além disso, viabilizar a implantação de espaços de acompanhamento pedagógico, psicopedagógico, psicológico e psiquiátrico, pois a saúde mental precisa ser vista de maneira interprofissional ${ }^{8}$.

\section{Referências}

1. World Health Organization. Fact sheets. [Internet]. 2020. [acesso em 2020 mar. 09]. Disponivel em: https://www.who.int/ news-room/fact-sheets/detail/depression

2. Organização Mundial de Saúde. Folha informativa - Depressão. [Internet]. 2018. Disponível em: https://www.paho.org/bra/index. php?option=com_content $\&$ view $=$ article\&id $=5635$

3. Ibanez G, Mercedes BPC, Vedana KGG, Miasso Al. Adesão e dificuldades relacionadas ao tratamento medicamentoso em pacientes com depressão. Rev Bras Enferm. 2014;67(4):556-62. doi: 10.1590/0034-7167.2014670409

\footnotetext{
4. Auerbach RP, Mortier P, Bruffaerts R, Alonso J, Benjet C, Cuijpers $\mathrm{P}$ et al. World Mental Health Surveys International College Student Project: Prevalence and distribution of mental disorders. J Abnorm Psychol. 2018;127(7):623-638. doi: 10.1037/ abn0000362

5. Barbosa LNF, Asfora GCA, Moura MC. Ansiedade e depressão e uso de substâncias psicoativas em jovens universitários. SMAD, Rev Eletrônica Saúde Mental Álcool Drog. 2020;16(1):1-8. doi: 10.11606/issn.1806-6976.smad.2020.155334
} 
6. Dias ACG, Carlotto RC, Oliveira CT, Teixeira MAP. Dificuldades percebidas na transição para a universidade Dificuldades na transição para a universidade. Rev Bras Orientac. 2019;20(1):1930. doi: 10.26707/1984-7270/2019v20n1p19

7. Fernandes MA, Vieira FER, Silva JS, Avelino FVSD, Santos JDM. Prevalência de sintomas ansiosos e depressivos em universitários de uma instituição pública. Rev Bras Enferm. 2018;71(suppl 5):2169-75. doi: 10.1590/0034-7167-2017-0752

8. Oliveira CT, Santos AS, Dias ACG. Expectativas de universitários sobre a universidade: sugestões para facilitar a adaptação acadêmica. Rev Bras Orientac. 2016;17(1):43-53.

9. Souza LK, Lourenço E, Santos MRG. Adaptação à universidade em estudantes ingressantes na graduação em psicologia. Psicol Educ. 2016;(42):5-48. doi: 10.5935/2175-3520.20150023 